\title{
Microwave pyrolysis of microalgae for high syngas production
}

\author{
D. Beneroso, J.M. Bermúdez, A. Arenillas, J.A. Menéndez* \\ Instituto Nacional del Carbón, CSIC, Apartado 73, 33080 Oviedo, Spain \\ * Corresponding author. Tel.: +34 985 118972; Fax: +34 985297672 \\ E-mail address: angelmd@,incar.csic.es
}

\begin{abstract}
The microwave induced pyrolysis of the microalga Scenedesmus almeriensis and its extraction residue was carried out at 400 and $800{ }^{\circ} \mathrm{C}$. The results show that it is possible to obtain a gas fraction with a high content (c.a. 50 vol.\%) in $\mathrm{H}_{2}$ from both materials, regardless of the pyrolysis temperature. Furthermore, an outstanding syngas production and high gas yields were achieved. The maximum syngas concentration obtained was c.a. 94 vol.\%, in the case of the pyrolysis of the residue at $800{ }^{\circ} \mathrm{C}$, indicating that the production of $\mathrm{CO}_{2}$ and light hydrocarbons was minimized. The same experiments were carried out in a conventional electric furnace in order to compare the products and yields obtained. It was found that microwave induced pyrolysis gives rise not only to higher gas yields but also to greater syngas and $\mathrm{H}_{2}$ production.
\end{abstract}

\section{Keywords}

Microwave; Pyrolysis; Microalgae; Bio-syngas; Bio-hydrogen 


\section{Introduction}

Microalgae are expected to become an important source of high-value products with several applications in a large number of areas of biotechnology (such as cosmetics, pharmacy and food) and, especially, in biofuels production (Brennan and Owende, 2010; Carriquiry et al., 2011; Chisti, 2007; Tabernero et al., 2012; Xu et al., 2011). The increasing interest in microalgae as a source of biofuel (the so-called third generation biofuel) is due to the several advantages that it offers over terrestrial oil crops. These advantages include: (1) an all-the-year-round production (which guarantees a considerably higher bio-oil production than oilseed crops); (2) the use of wastewater as a source of nutrients; (3) the elimination of the need for herbicides or pesticides; and (4) their possible cultivation in brackish water or non-arable land, resulting in a minimisation of the associated environmental impact (Brennan and Owende, 2010; Chisti, 2007). For these reasons and with the expected increase in liquid biofuel consumption, microalgae seem to be the only biofuel source able to completely replace conventional fuels (Chisti, 2007; Ferrel and Sarisky-Reed, 2010; Tabernero et al., 2012).

However, a number of technical and economic factors, such as species selection, photosynthetic efficiency and production costs, have so far impeded the industrial development of biofuels from microalgae (Brennan and Owende, 2010; Carriquiry et al., 2011; Xu et al., 2011). Before it can be commercially viable, it is necessary to reduce the production costs of microalgae-based biofuels from their current levels, which far exceed the prices of petroleum fuels (Brennan and Owende, 2010; Carriquiry 
et al., 2011; Tabernero et al., 2012). Several economic analyses and LCA studies have been carried out with the aim of identifying weaknesses and potential improvements that could be made in the production processes in order to achieve a more sustainable and economically feasible production process (Campbell et al., 2011; Delrue et al., 2012; Ferrel and Sarisky-Reed, 2010; Harun et al., 2011; Lardon et al., 2009; Tabernero et al., 2012; Xu et al., 2011). Since Chisti proposed the application of the biorefinery concept to microalgae-based fuel production (Chisti, 2007), all of these studies have emphasized the importance of exploiting the residues generated in the production process, especially those produced after oil extraction.

Thermochemical conversion through pyrolysis has been proposed for both microalgae and their extraction residues in order to obtain three fractions: solid (bio-char), liquid (bio-oils) and gaseous (bio-gas). Conventional pyrolysis (CP) is mainly focused on the production of liquid products (Brennan and Owende, 2010; Miao and Wu, 2004; Miao et al., 2004). In the particular case of the pyrolysis of microalgae biomass, the studies performed to date have been aimed at maximising the yields of this fraction (Campanella et al., 2012; Du et al., 2011; Grierson et al., 2011; Hu et al., 2012; Miao et al., 2004; Thangalazhy-Gopakumar et al., 2012; Xu et al., 2011). However, although the pyrolysis oils obtained from microalgae are superior to those obtained from other biomass feedstocks (Du et al., 2011; Miao et al., 2004; Tabernero et al., 2012), these oils are acidic, unstable, and. viscous. Moreover, they contain solids, chemically dissolved water and significant proportions of nitrogen compounds, making it necessary to apply additional upgrading processes for the oils to be useful for biofuel production 
(Brennan and Owende, 2010; Campanella et al., 2012; Sanchez-Silva et al., 2013; Wang et al., 2013).

An attractive alternative for the pyrolysis of microalgae biomass could be that of biogas production, with the aim of obtaining the maximum possible amount of high-value components of which synthesis gas (syngas) is just one example. There have recently appeared new ways to exploit the potential of syngas from waste pyrolysis. For example, the SYNPOL project will enable the EU to take a global lead in syngas fermentation technology for waste revalorisation and the production of new materials such as biopolymers (http://www.synpol.org/). For this purpose, microwave-induced pyrolysis (MIP) seems to be the way forward. Previous studies on the MIP of biomass have shown the ability of this technology to produce higher yields of the gas fraction and a greater concentration of bio-syngas and bio-hydrogen in this gaseous product than CP (Domínguez et al., 2007; Fernández et al., 2010; Fernández et al., 2009), probably due to the presence of microplasmas and hot spots formed during microwave heating (Menéndez et al., 2011). Moreover, MIP presents several advantages over CP, such as a better control over the process, faster heating or lower temperatures (Du et al., 2011; Fernández et al., 2010; Fernández et al., 2009; Hu et al., 2012; Luque et al., 2012).

To the best of our knowledge, there have been no studies on the MIP of microalgae with the aim of maximising gas production and the proportion of high-value components, such as $\mathrm{H}_{2}$, in the gas fraction. The novelty of the present work is to study and compare the CP and MIP of the microalga Scenedesmus almeriensis and its extraction residue, so as to obtain the maximum possible gas yield and the highest bio-syngas and bio- 
hydrogen proportions in this fraction. In addition, this is the first time that an extraction residue of microalgae has been subjected to a revalorization process for this purpose.

\section{Materials and methods}

\subsection{Materials}

The microalga selected for this study was Scenedesmus almeriensis, supplied by Exeleria, S.L. The algae biomass was dried in the harvesting facilities before being supplied to the lab for the experiments. The microalga was used both as received and after being subjected to an extraction process. The extraction was carried out using methanol as solvent, at a temperature of $50^{\circ} \mathrm{C}$ under magnetic stirring. After the extraction, the extract and the residue were separated by filtration. Table 1 shows the elemental and proximate analysis of the microalga and the extraction residue, which will be labelled as A and R respectively.

Table 1. Elemental and proximate analysis of the microalgae (A) and the extraction residue $(\mathrm{R})$

\begin{tabular}{|c|c|c|c|c|c|c|c|c|}
\hline & \multicolumn{3}{|c|}{ Proximate Analysis (wt.\%) } & \multicolumn{5}{|c|}{ Ultimate Analysis (wt.\%) $^{\mathrm{a}}$} \\
\hline & Moisture & $\mathrm{Ash}^{\mathrm{a}}$ & Volatile matter $^{\mathrm{a}}$ & $\mathrm{C}$ & $\mathrm{H}$ & $\mathrm{N}$ & $\mathrm{S}$ & $\mathrm{O}^{\mathrm{b}}$ \\
\hline A & 6.5 & 18.1 & 70.7 & 43.8 & 5.7 & 8.1 & 0.6 & 23.6 \\
\hline $\mathrm{R}$ & 5.8 & 19.5 & 69.8 & 42.4 & 5.6 & 8.8 & 0.7 & 23.0 \\
\hline
\end{tabular}




\subsection{Experimental procedure}

The pyrolysis of $\mathrm{A}$ and $\mathrm{R}$ was carried out in a conventional electrical furnace and in a single mode microwave oven at 400 and $800^{\circ} \mathrm{C}$. About $4 \mathrm{~g}$ of sample was placed in a quartz reactor. The reactor was purged with He for 30 minutes at a flow rate of $100 \mathrm{~mL} \mathrm{STP} \mathrm{min}^{-1}$. The helium flow rate was then set to $20 \mathrm{~mL} \mathrm{STP} \mathrm{min}^{-1}$ for the pyrolysis experiments.

In the case of $\mathrm{CP}$, the reactor with the sample was introduced into the conventional furnace previously heated up to the desired pyrolysis temperature, to enable the temperature of the sample to rise rapidly. In the case of MIP, the quartz reactor was placed in the centre of the microwave guide before being subjected to irradiation. Details of this experimental set-up have been described elsewhere (Domínguez et al., 2005). Since biomass is a poor microwave absorber, it is necessary to mix it with an appropriate microwave absorber to achieve the high temperatures required for pyrolysis (Domínguez et al., 2005; Fernández et al., 2009). The char obtained from the pyrolysis of the sample at $800{ }^{\circ} \mathrm{C}$ in the electrical furnace, was used as microwave absorber in an absorber:sample proportion of about 30:70 wt.\%. This ratio was selected after several preliminary experiments, which showed that this was the lowest ratio that would allow the biomass to be heated to the desired temperature while avoiding the thermal runaway effect which could result from microwave heating. An additional experiment was performed with graphite dust as microwave absorber in order to study the possible catalytic effect of the char. 
In the electric furnace the temperature was monitored by means of a thermocouple of type $\mathrm{K}$, whereas in the microwave oven, due to the inherent difficulties involved in measuring this parameter in microwave devices (Menéndez et al., 1999), the temperature of the sample, which was regulated by manual adjustment of the microwave power $\left(250 \mathrm{~W}\right.$ and $950 \mathrm{~W}$ to reach $400{ }^{\circ} \mathrm{C}$ and $800{ }^{\circ} \mathrm{C}$ respectively), was monitored by means of an infrared optical pyrometer. MIP temperature was measured following a correction procedure described previously by our research group (Menéndez et al., 1999). The time-temperature profiles for the samples are included in the Supplementary Data document. In the electric furnace, the temperature started to rise as soon as the reactor had been placed inside the furnace, while in the microwave oven, it took about 5-7 minutes to start to rise, since during this time only the microwave absorber was heated by the microwave irradiation. The rest of the sample was heated by conduction as the microwave absorber temperature rose.

The experiments were labelled $\mathrm{X}-\mathrm{YZ}$, where $\mathrm{X}$ was the material pyrolysed ( $\mathrm{A}$ in the case of the microalga and $\mathrm{R}$ in the case of the extraction residue), $\mathrm{Y}$ was the heating device used to carry out the pyrolysis ( $\mathrm{C}$ for $\mathrm{CP}$ and $\mathrm{M}$ for MIP), and $\mathrm{Z}$ was the pyrolysis temperature $\left(400\right.$ or $\left.800{ }^{\circ} \mathrm{C}\right)$. As an example, A-M400 is the pyrolysis experiment performed on microalga by means of microwave heating at $400{ }^{\circ} \mathrm{C}$.

The total time for the experiments was chosen on the basis of the outlet flow rate of the pyrolysis gases. The experiments were considered completed once the flow rate of the

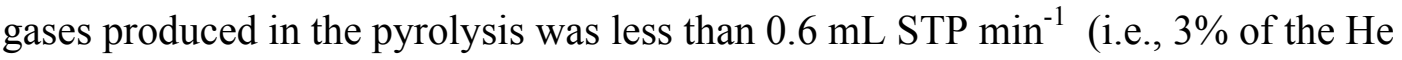
flow rate). 
The volatiles evolved from the pyrolysis of the sample were passed through a condensing system, cooled by a cryogenic solution of water and $\mathrm{NaCl}$. The bio-oil fraction was recovered from the condensing system by dissolving it in dichloromethane. It was then subjected to further evaporation of the solvent at $40{ }^{\circ} \mathrm{C}$. This fraction was not analysed, since it is was considered to be outside the scope of this work. The noncondensable gases were collected, at intervals of 10 minutes, in Tedlar sample bags with a polypropylene fitting for sampling and then analysed by gas chromatography. The composition of the gaseous fraction can be determined from the composition of each bag and the He flowrate (which is constant at the inlet and the outlet of the reactor because He cannot be produced or consumed in the pyrolysis process). The solid and oil fraction yields were calculated from the weight of each fraction, while the gas yield was evaluated by difference. In the case of the solid fraction, it is impossible to discern the amount of $\mathrm{CO}_{2}$ reacting with the initial microwave absorber or the char that is being formed in the pyrolysis (which also acts as new microwave absorber). In consequence, the yield of solid fraction has been calculated assuming that the gasification of the initial microwave absorber is negligible. The experiments were performed in duplicate to check the repeatability. The errors came to less than $5 \%$ both for the yields and the gas composition. 


\section{Results and discussion}

\subsection{Gas production}

As was explained in the Experimental section, all the experiments were run until the gas produced was less than $0.6 \mathrm{~mL} \mathrm{~min}^{-1}$. However, pyrolysis could be concluded before this point was reached because of the low amount of gas produced (see Figure 1). Another possibility was to set the end of pyrolysis at a certain percentage of the maximum value of the outlet flow rate. In this study, the time selected for calculating the production, yields and gas compositions was the point at which the gas outlet flow rate had fallen to $5 \%$ of the maximum amount of gas produced during the experiment $\left(t_{5 \%}\right)$. Figures $1 \mathrm{a}$ and $1 \mathrm{~b}$ show the evolution of the outlet flow rate (L STP $\min ^{-1} \mathrm{~g}^{-1}$ ), normalised per gram of sample, during the pyrolysis of A and R, respectively. It can be seen that A-M400 and A-M800 yielded the highest outlet flow rate value, around 0.035 L STP $\min ^{-1} \mathrm{~g}^{-1}$.

At lower temperature $\left(400^{\circ} \mathrm{C}\right)$, MIP yielded a much higher outlet flow rate (Figure 1) and gas production (Figure 2) than CP. This outstanding result highlights the advantage of using MIP rather than CP for gas production, since it is possible to obtain much higher values of gas production at much lower temperatures due to the presence of hot spots and microplasmas in MIP. These hot spots are at much higher temperatures than the overall temperature of the system $\left(400{ }^{\circ} \mathrm{C}\right)$. This phenomenon allows the development of processes that will not take place at the overall temperature of the bulk, i.e., microwave irradiation has a pseudo-catalytic effect (Menéndez et al., 2011; Zhang 
et al., 2003). At $800^{\circ} \mathrm{C}$, the same trend is observed although during the first 5 minutes of experiment A-C800, CP furnishes a slightly higher outlet flow rate, which could be attributed to the fact that the microwave heating of the sample is delayed since, initially, only the microwave absorber is heated by means of microwave irradiation.
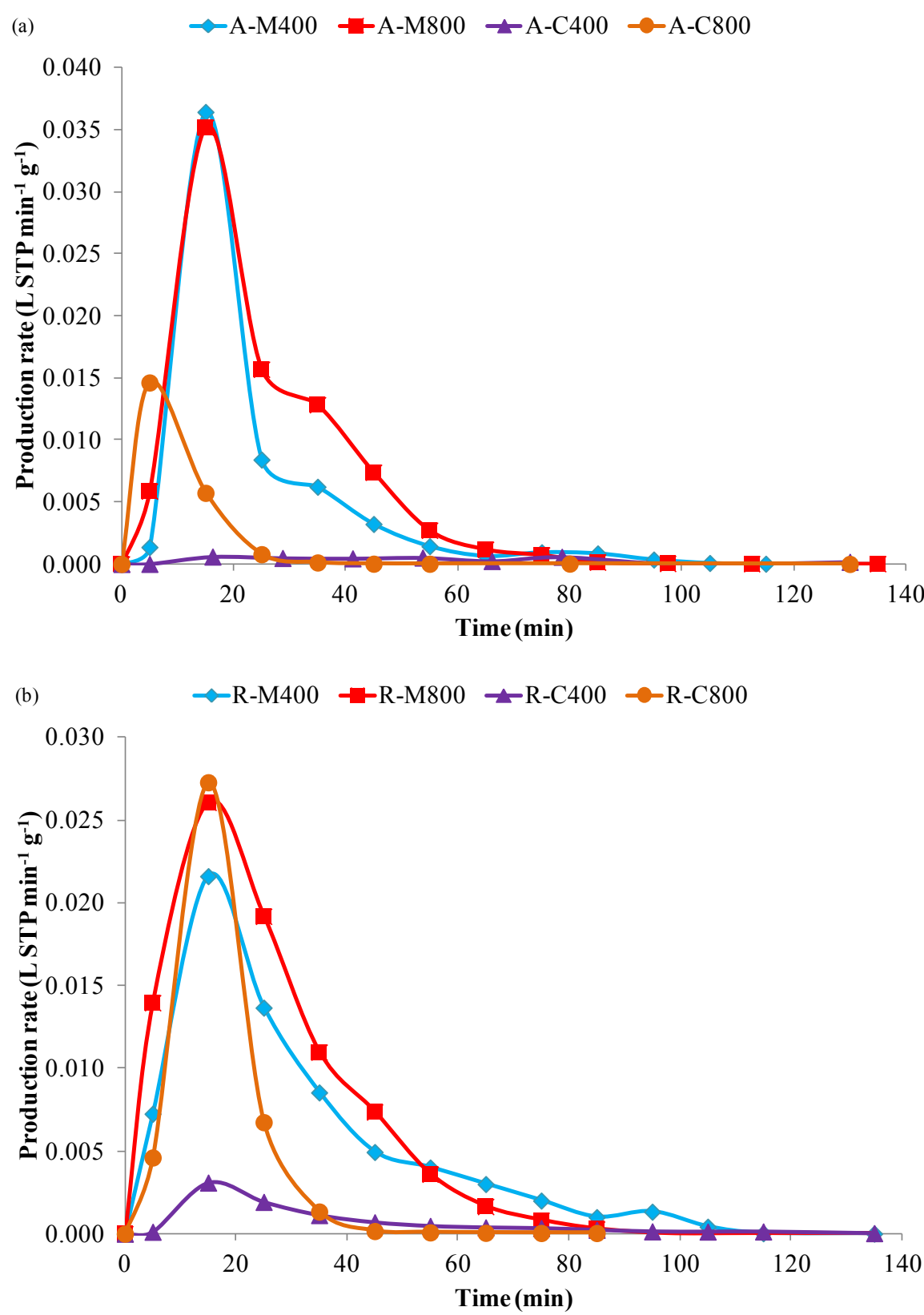

Figure 1. Evolution of the outlet flow rate (L STP $\left.\min ^{-1} \mathrm{~g}^{-1}\right)$ during the different pyrolysis experiments of (a) the microalga and (b) residue. 
Gas production is also affected by the temperature of pyrolysis. The higher the temperature is, the higher the production, although this difference is much less noticeable in the case of microwave heating. If both materials are compared, R shows higher gas production values than $\mathrm{A}$ in all cases, particularly in the $\mathrm{CP}$ experiments.
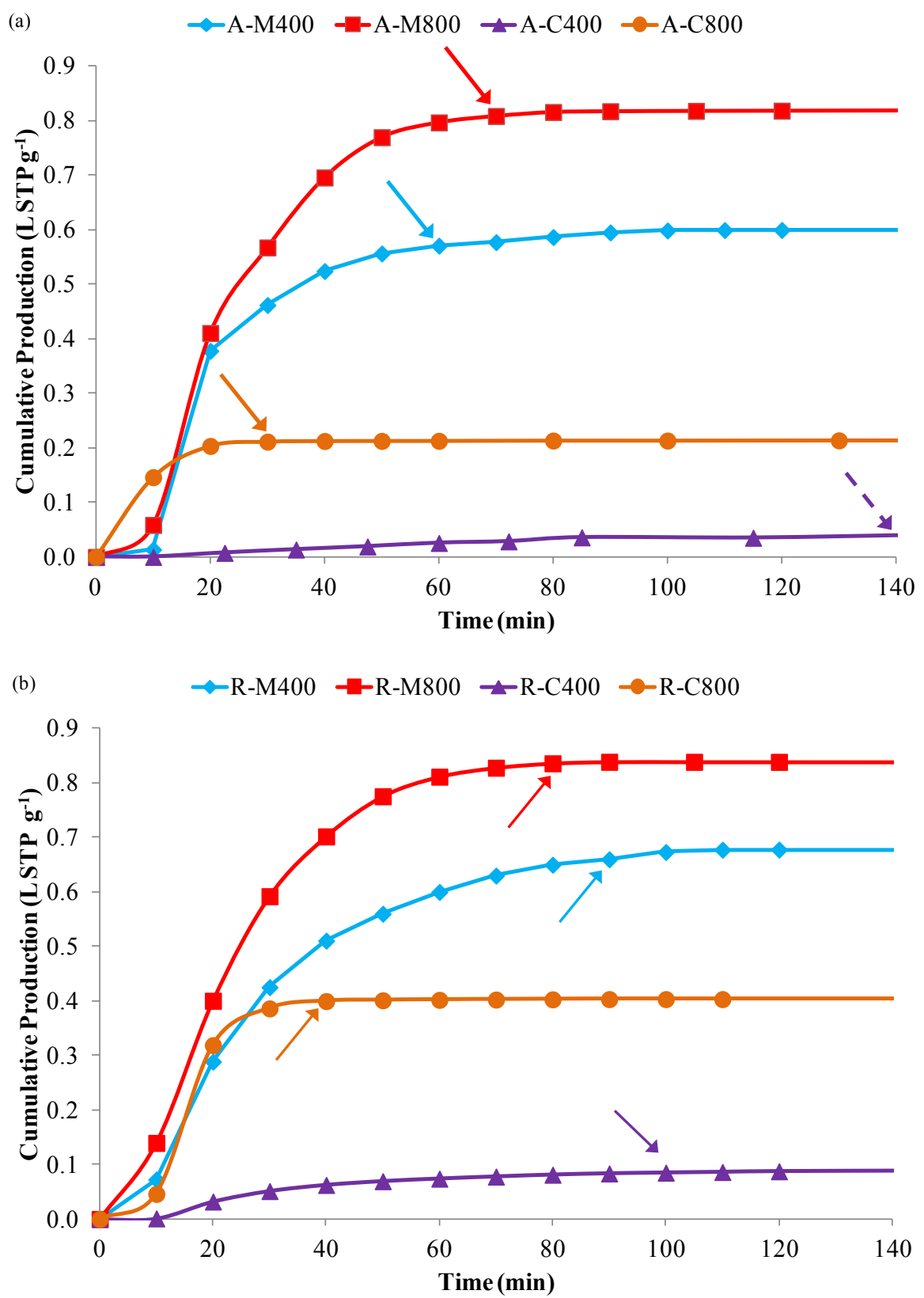

Figure 2. Cumulative production ( $\mathrm{L} \mathrm{STP} \mathrm{g}^{-1}$ ) for the pyrolysis experiments of (a) the microalga and (b) residue. $t_{5 \%}$ values for each of the experiments are displayed by arrows. 
Although in some cases the time required for CP is less than for MIP, suggesting an $a$ priori energy saving, Figure 2 shows that the cumulative production achieved is far greater with microwave heating even at $400{ }^{\circ} \mathrm{C}$. The $\mathrm{t}_{5 \%}$ values are indicated by arrows. In the case of A-C400, it was not possible to reduce the flow rate to $5 \%$ of the maximum flow rate after 140 minutes because the maximum flow rate was very low to begin with.

\subsection{Product yields}

The char, oil and gas yields for A and R under different pyrolysis conditions are presented in Figure 3. From the yield data it can be seen that the distribution of products differs considerably depending on several factors. With the same thermal treatment, A and R show similar yields of solids. However, the oil and gas yields are strongly dependent on the heating method and the raw material to be pyrolysed.

$\square$ Char $\square$ Liquid $\square$ Gas

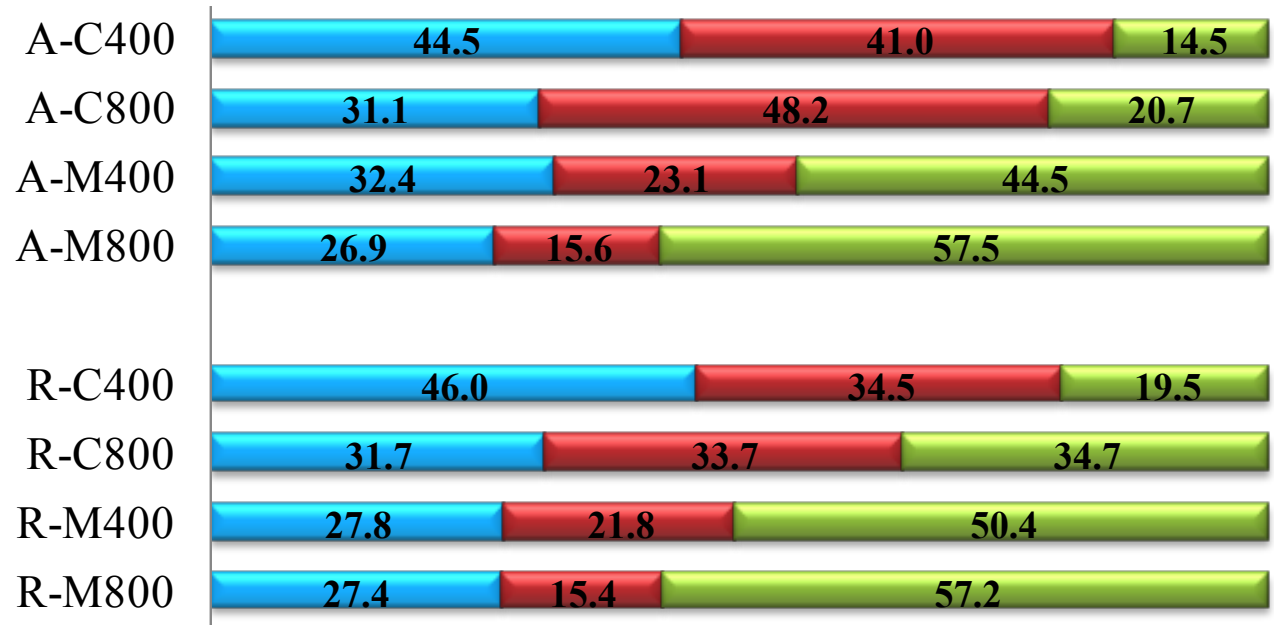

Figure 3. Fraction yields (wt.\%) from the pyrolysis of microalgae and its residue as a function of the heating method and the pyrolysis temperature. 
$\mathrm{CP}$ always gives higher oil yields and lower gas yields than MIP, as has been stated in other studies on biomass materials (Domínguez et al., 2007; Fernández et al., 2009). Typical oil yields of up to $75 \mathrm{wt} . \%$ at $500{ }^{\circ} \mathrm{C}$ have been reported for conventional biomass fast pyrolysis (Bridgwater, 2012), whereas in the experiments here reported the highest value attained in an electric furnace was around 48 wt. $\%$ at $800{ }^{\circ} \mathrm{C}$. However, MIP always produced a greater gas yield than $\mathrm{CP}$ as previously demonstrated by our research group (Domínguez et al., 2007; Fernández et al., 2010; Fernández et al., 2009).

It can be seen from Figure 3 that the gas yield from the pyrolysis of $\mathrm{R}$ is much higher than for A, except in the case of experiment A-M800 where it is only slightly higher. This could be due to the fact that, with the extraction of the residue from the microalga, heavy compounds such as lipids are removed, resulting in an oil fraction which is easier to crack.

The effect of temperature was also assessed. It was observed that an increase in pyrolysis temperature leads to a decrease in the solid fraction and an increase in the gas yield. This can be attributed to an increase in the devolatilization of the organic material and the secondary cracking of pyrolysis vapours into incondensable gases. It is to be noted that at low temperature $\left(400^{\circ} \mathrm{C}\right)$, MIP gives rise to an exceptional gas yield compared to $\mathrm{CP}$ (307\% higher in the case of A pyrolysis). This result highlights one of the main advantages of using microwave heating since typical gas fraction yields via conventional fast pyrolysis are about $10 \mathrm{wt} . \%$ (Bridgwater, 2012). Nevertheless, the gas yield difference between conventional or microwave heating decreases at the higher temperature $\left(800^{\circ} \mathrm{C}\right)$ although the difference is still appreciable $(278 \%$ higher in the 
case of A pyrolysis). It should also be noted that the microalga Scenedesmus almeriensis utilised in this study gives a gas yield of $45 \mathrm{wt} . \%$ for the experiment AM400, which is higher than that obtained with other types of microalgae such as Chlorella sp. when subjected to MIP at even higher temperatures (Du et al., 2011).

To sum up, these results highlight that microalgae, and particularly the residues obtained after the extraction process, are very attractive substrates for obtaining gaseous products by means of pyrolysis, especially by MIP.

\subsection{Gas fraction analysis}

The effects of pyrolysis temperature and heating method on the composition of the gas fraction from CP and MIP are shown in Figure $4 \mathrm{a}$ and $4 \mathrm{~b}$ respectively. The main gases obtained are $\mathrm{H}_{2}, \mathrm{CH}_{4}, \mathrm{C}_{2} \mathrm{H}_{4}, \mathrm{C}_{2} \mathrm{H}_{6}, \mathrm{CO}$ and $\mathrm{CO}_{2}$. Thus, hydrogen is produced by the cracking of volatiles and reforming reactions; and methane, ethylene and ethane by cracking and depolymerization reactions. Finally, carbon monoxide and carbon dioxide were obtained from the depolymerisation of oxygenated organic compounds of biomass, the dehydrogenation of phenolic groups, the cracking of carbonyl groups, the rupture of oxygenated heterocycles or secondary char/hydrocarbon gasification reactions (reactions $1,2,4,7,8$ and 9 in Table 2). It should be noted, too, that pyrolytic gases may participate in secondary reactions that might modify the composition of the outlet gas." 
Table 2. Main chemical reactions involved in the pyrolysis process.

\begin{tabular}{clc}
\hline Number & \multicolumn{1}{c}{ Reaction } & $\Delta \mathrm{H}_{298 \mathrm{~K}}\left(\mathrm{~kJ} \mathrm{~mol}^{-1}\right)$ \\
\hline 1 & $\mathrm{CH}_{4}+\mathrm{CO}_{2} \leftrightarrow 2 \mathrm{H}_{2}+2 \mathrm{CO}$ & 247 \\
2 & $\mathrm{CH}_{4}+\mathrm{H}_{2} \mathrm{O} \leftrightarrow 3 \mathrm{H}_{2}+\mathrm{CO}$ & 205 \\
3 & $\mathrm{CH}_{4} \rightarrow \mathrm{C}+2 \mathrm{H}_{2}$ & 173 \\
4 & $\mathrm{CO}_{2}+\mathrm{C} \leftrightarrow 2 \mathrm{CO}$ & 136 \\
5 & $\mathrm{C}_{2} \mathrm{H}_{6} \leftrightarrow \mathrm{C}_{2} \mathrm{H}_{4}+\mathrm{H}_{2}$ & \\
6 & $\mathrm{C}_{\mathrm{n}} \mathrm{H}_{\mathrm{m}} \rightarrow \mathrm{n} \mathrm{C}+(\mathrm{m} / 2) \mathrm{H}_{2}$ & \\
7 & $\mathrm{C}_{\mathrm{n}} \mathrm{H}_{\mathrm{m}}+\mathrm{n} \mathrm{H}_{2} \mathrm{O} \leftrightarrow \mathrm{n} \mathrm{CO}+(\mathrm{n}+\mathrm{m} / 2) \mathrm{H}_{2}$ & \\
8 & $\mathrm{C}_{\mathrm{n}} \mathrm{H}_{\mathrm{m}}+\mathrm{n} \mathrm{CO} \mathrm{CO}_{2} \leftrightarrow 2 \mathrm{n} \mathrm{CO}+(\mathrm{n} / 2) \mathrm{H}_{2}$ & \\
9 & $\mathrm{C}+\mathrm{H}_{2} \mathrm{O} \leftrightarrow \mathrm{CO}+\mathrm{H}_{2}$ & \\
\hline
\end{tabular}

In $\mathrm{CP}$ a gas rich in $\mathrm{CO}_{2}$ is obtained at $400{ }^{\circ} \mathrm{C}(67 \%$ and $77 \%$ for $\mathrm{A}$ and $\mathrm{R}$, respectively). From the results shown in Figure 4a, it is clear that the $\mathrm{CO}_{2}$ concentration is highly dependent on the pyrolysis temperature, since at $800{ }^{\circ} \mathrm{C}$ it is reduced to c.a. $12 \%$. A positive effect on the total amount of gases generated is exerted when the temperature is increased, as is confirmed in Figures 1-2. However, the increase in carbon dioxide produced at $800{ }^{\circ} \mathrm{C}$ is negligible compared to the other gases. There is therefore a decrease in $\mathrm{CO}_{2}$ concentration, as has been reported for several agricultural residues (Encinar et al., 1996; Zanzi et al., 2002). 
(a)

$\nabla \mathrm{A}-\mathrm{C} 400 \Delta \mathrm{R}-\mathrm{C} 400 \quad \mathrm{~A}-\mathrm{C} 800 \quad \square \mathrm{R}-\mathrm{C} 800$

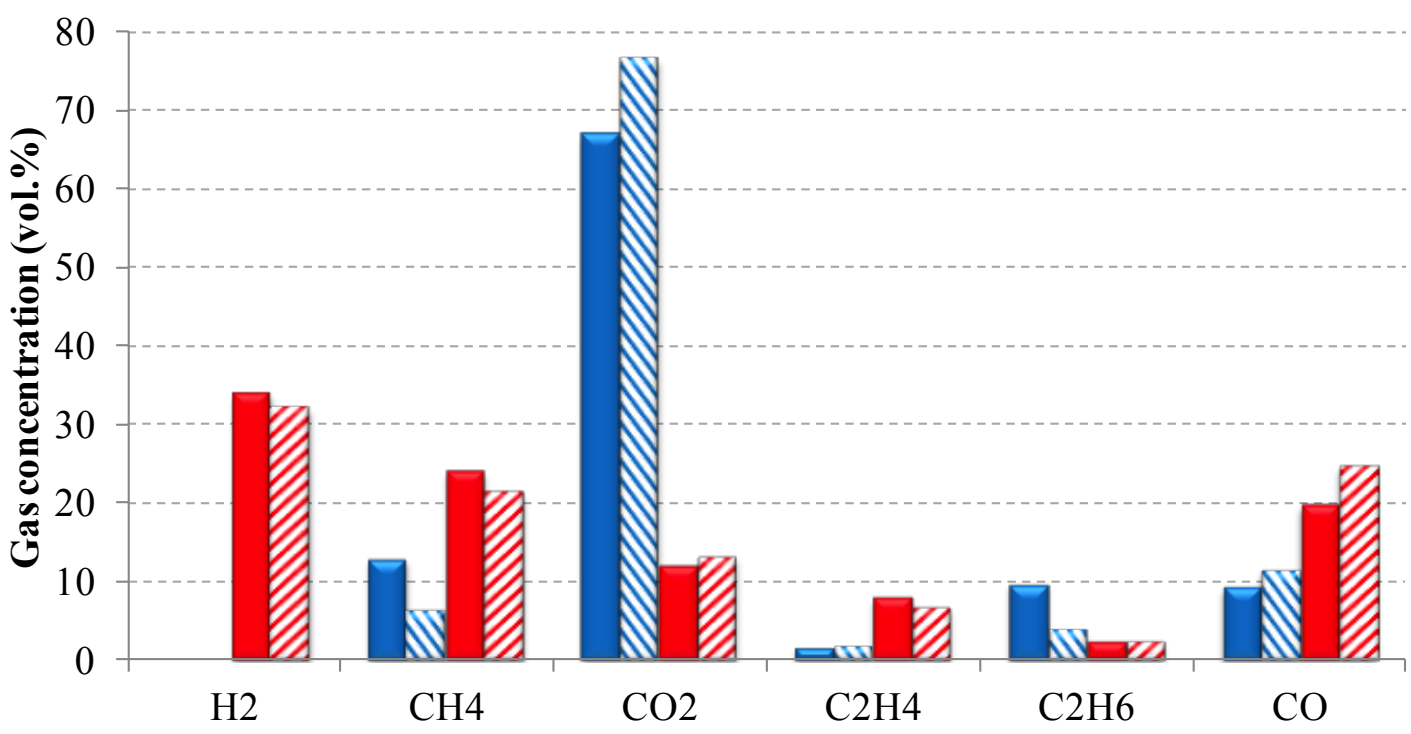

(b)

$\nabla \mathrm{A}-\mathrm{M} 400 \quad \nabla \mathrm{R}-\mathrm{M} 400 \quad \mathrm{~A}-\mathrm{M} 800 \quad \square \mathrm{R}-\mathrm{M} 800$

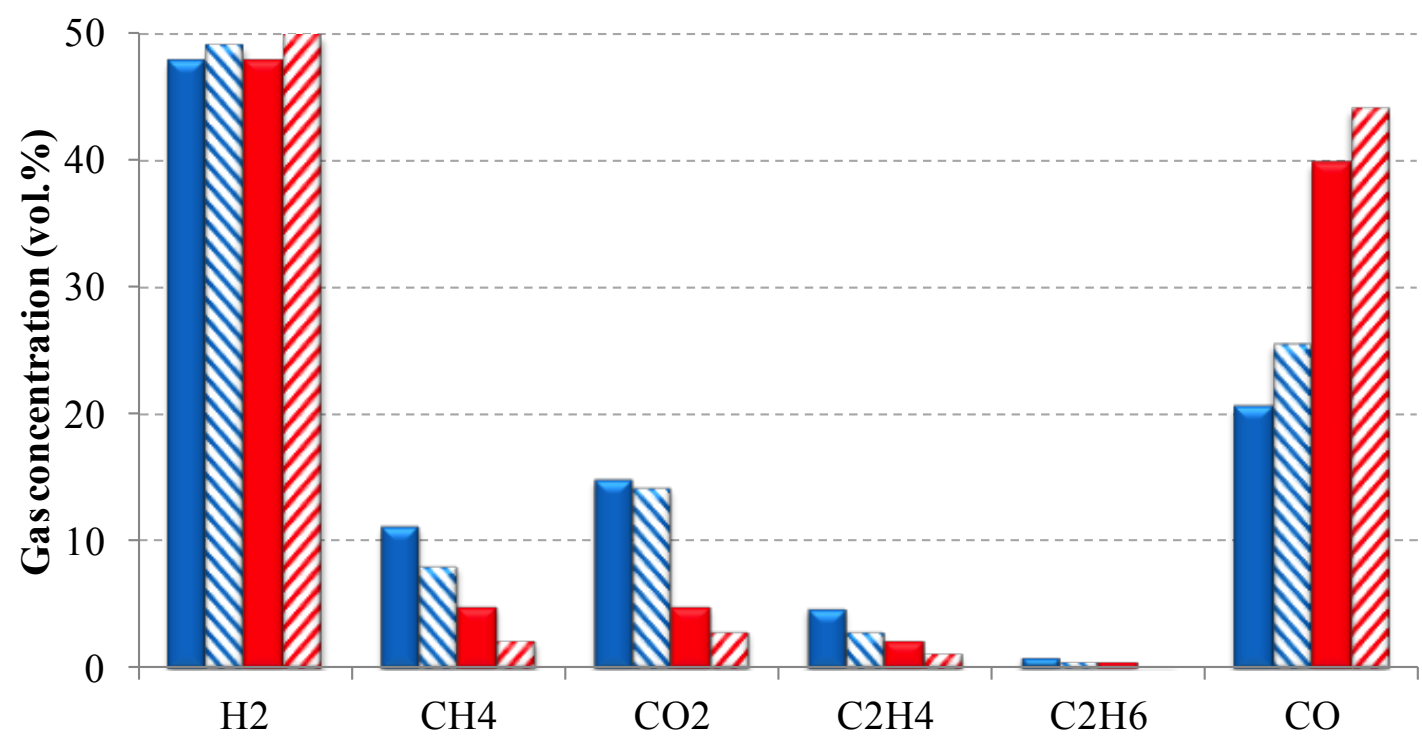

Figure 4. Gas composition (vol.\%) of the gas fraction produced from: (a) the CP and (b) MIP of A and R at different temperatures.

The $\mathrm{H}_{2}, \mathrm{CO}, \mathrm{CH}_{4}$ and $\mathrm{C}_{2} \mathrm{H}_{4}$ concentrations on the other hand, increase at $800{ }^{\circ} \mathrm{C}$. A higher temperature favours the cracking of the hydrocarbons (Table 2, Reactions 3 and 6) and reforming reactions (Table 2, Reactions 1-2 and 7-8) in the gas fraction, which leads to an increase in the yield of $\mathrm{H}_{2}$ and $\mathrm{CO}$. Hydrogen is not detected at $400{ }^{\circ} \mathrm{C}$ for any material, although it is the main gas at $800^{\circ} \mathrm{C}$ with a yield at this temperature of 
approximately $30 \%$. The carbon monoxide concentration starts at $9 \%$ for A and at $11 \%$ for $\mathrm{R}$ pyrolysis and reaches a value of $20 \%$ and $25 \%$ respectively at $800{ }^{\circ} \mathrm{C}$, which means that its concentration has approximately doubled with the doubling of the temperature. As a consequence, the best value achieved for the total concentration of $\mathrm{CO}+\mathrm{H}_{2}$ (syngas) by means of $\mathrm{CP}$ is $56.4 \%$ corresponding to $\mathrm{R}-\mathrm{C} 800$.

The contribution of methane varies from $13 \%$ at $400{ }^{\circ} \mathrm{C}$ to $24 \%$ at $800{ }^{\circ} \mathrm{C}$ for $\mathrm{A}$ and from $6 \%$ to $21 \%$ in the case of $\mathrm{R}$. The $\mathrm{C}_{2} \mathrm{H}_{6}$ concentration is reduced at $800{ }^{\circ} \mathrm{C}$ probably due to the dehydrogenation of ethane (Table 2, Reactions 5). In the case of $\mathrm{C}_{2} \mathrm{H}_{4}$, although its concentration is very low at $400{ }^{\circ} \mathrm{C}(2 \%$ for both materials), it increases by more than three times at $800{ }^{\circ} \mathrm{C}$.

As can be seen from Figure $4 \mathrm{~b}$, the product distribution with MIP is qualitatively very different from that obtained with CP. It is evident therefore that microwave heating favours the formation of $\mathrm{CO}+\mathrm{H}_{2}$ (syngas). Hydrogen is the main gas produced regardless of the raw material and pyrolysis temperature. The high $\mathrm{H}_{2}$ concentration obtained in the case of A-M400 (48\%) is even higher than that obtained at $800{ }^{\circ} \mathrm{C}$ by $\mathrm{CP}$ (A-C800, 34\%), but the concentration is greater when pyrolysing $\mathrm{R}$. The highest $\mathrm{H}_{2}$ content achieved is $50 \%$, corresponding to the R-M800 experiment. This remarkable result can again be attributed to the presence of hot spots and microplasmas in MIP, and their pseudo-catalytic effect.

The carbon monoxide concentration is also higher in MIP and increases with temperature, especially in the case of R. Experiment R-M400 releases a CO 
concentration of $26 \%$ compared to the $44 \%$ generated in R-M 800 . Thus, taking into account that $\mathrm{H}_{2}$ remains practically constant for all experiments, the variability in $\mathrm{CO}$ leads to gas mixtures with different $\mathrm{H}_{2} / \mathrm{CO}$ ratios, as is shown in Table 3 . These results, in combination with the quicker heating rates provided by microwave heating, give MIP another advantage of MIP over CP. In MIP it is possible to increase or decrease temperatures very quickly, simply by adjusting the power emitted. This allows the composition of the syngas obtained to be easily changed from low to high values of $\mathrm{H}_{2} / \mathrm{CO}$ or vice versa. In $\mathrm{CP}$, the heating inertia rules out this possibility. With microwave heating, the $\mathrm{H}_{2} / \mathrm{CO}$ ratio decreases when the temperature increases. The opposite occurs if heating is carried out in the conventional electric furnace. Moreover, the total concentration of syngas is much higher in the gases obtained by MIP than in $\mathrm{CP}$, with values as high as $93.8 \%$ in the case of R-M800 compared to values of $56.4 \%$ for R-C800.

In contrast, the concentrations of $\mathrm{CO}_{2}, \mathrm{CH}_{4}, \mathrm{C}_{2} \mathrm{H}_{4}$ and $\mathrm{C}_{2} \mathrm{H}_{6}$ formed by MIP decrease with the increase in temperature. If the $\mathrm{CO}_{2}$ concentrations resulting from the two heating methods at the same pyrolysis temperature are compared, it can be seen that the $\mathrm{CO}_{2}$ concentrations from MIP are always lower than those from $\mathrm{CP}$, and that the lower the temperature, the greater the difference. This is because the reaction between the char and $\mathrm{CO}_{2}$ generates $\mathrm{CO}$ (Table 2, Reaction 4) and because dry reforming reactions (Table 2, Reactions 1 and 8) are favoured at high temperatures. 
Table 3. Synthesis gas concentration and its $\mathrm{H}_{2} / \mathrm{CO}$ ratio from the conventional and microwave pyrolysis of $\mathrm{A}$ and $\mathrm{R}$ at different temperatures.

\begin{tabular}{|c|c|c|c|c|c|c|c|c|}
\hline & \multicolumn{4}{|c|}{ Microalgae } & \multicolumn{4}{|c|}{ Residue of microalgae } \\
\hline & $\mathrm{A}-\mathrm{C} 400$ & A-C 800 & A-M400 & A-M800 & $\mathrm{R}-\mathrm{C} 400$ & $\mathrm{R}-\mathrm{C} 800$ & R-M400 & R-M800 \\
\hline $\begin{array}{c}\text { Syngas } \\
\text { (vol.\%) }\end{array}$ & 9.2 & 53.5 & 68.5 & 87.7 & 11.4 & 56.4 & 74.5 & 93.8 \\
\hline $\mathrm{H}_{2} / \mathrm{CO}$ & 0 & 1.7 & 2.3 & 1.2 & 0 & 1.3 & 1.9 & 1.1 \\
\hline
\end{tabular}

On the whole, the methane contents in the CP gases are higher than in the case of MIP which indicates that reforming reactions involving $\mathrm{CH}_{4}$ (Table 2, Reactions 1-2) are favoured in MIP (Wang et al., 2009). The presence of $\mathrm{C}_{2}$ compounds in MIP is scarcely noticeable. In conventional heating, the heat flow goes from the walls of the reactor to the sample, so the temperature is higher in the reactor than inside the bulk sample. This creates favourable conditions for the homogeneous cracking of the liquid components, leading to an increase in the hydrocarbon content of the pyrolysis gas. In contrast, when microwave heating is used, the heat is produced by the interaction of the sample with the electromagnetic field, so the temperature is higher in the sample than in the reactor, favouring the heterogeneous catalytic decomposition of hydrocarbons (Table 2, Reactions 3 and 6) (Domínguez et al., 2006). This might explain why the value of the total light hydrocarbon yield $\left(\mathrm{CH}_{4}+\mathrm{C}_{2} \mathrm{H}_{6}+\mathrm{C}_{2} \mathrm{H}_{4}\right)$ is higher in all of the experiments carried out in the electric furnace for both materials. 
Regarding the influence of the extraction procedure on the gas composition, there are no big differences, possibly due to the similar proximate and ultimate compositions of the microalga and its extraction residue. Therefore the influence of pyrolysed material is not a meaningful characteristic in this sense.

\subsection{Catalytic effects of the microwave absorber}

Besides the pseudo-catalytic effect resulting from the microplasmas caused by microwave heating (Menéndez et al., 2011; Zhang et al., 2003), the metallic content of the char used as microwave absorber can catalyse reforming reactions or the decomposition of hydrocarbons, and favour the generation of large amounts of hydrogen in MIP. A semiquantitative analysis of the metal content of the microwave absorber was performed using an ICP-MS 7700x Agilent, finding that the main metals present in the material are: $\mathrm{K}(3$ wt. \%), $\mathrm{Mg}(2$ wt. \%), Na (1 wt. \%), Fe (7000 ppm), Sr and $\mathrm{Mn}$ (1500 ppm), Si (1000 ppm), Ba (300 ppm) and $\mathrm{Cu}$ and $\mathrm{Zn}(200 \mathrm{ppm})$. To confirm or discard this catalytic effect, three additional experiments were performed. The A-M400 experiment was repeated using graphite dust as microwave absorber (the experiment was labelled as A-M400-G) in order to study the MIP without the presence of the metallic content of the char. Experiments A-C400 and A-C 800 were repeated with the addition of the char (the experiments were labelled as A-C400-Abs and AC800-Abs), in the same proportion as in MIP, to determine whether any change occurred in the gas composition due to the presence of the metallic content of the char. The results are shown in Figure 5. As can be seen, there are no significant differences when graphite is used as microwave absorber in the MIP or when the char is added to 
the $\mathrm{CP}$, which suggests that the metal content of the char has no substantial catalytic effect. The only noteworthy difference is the change in the proportions of $\mathrm{CO}$ and $\mathrm{CO}_{2}$ in MIP with the different absorbers. With char, the CO concentration is higher than with graphite dust, while in the case of the $\mathrm{CO}_{2}$ the highest concentration results from mixing the microalga is achieved with a mixture of microalga and graphite dust. This may be related to the gasification of the char.

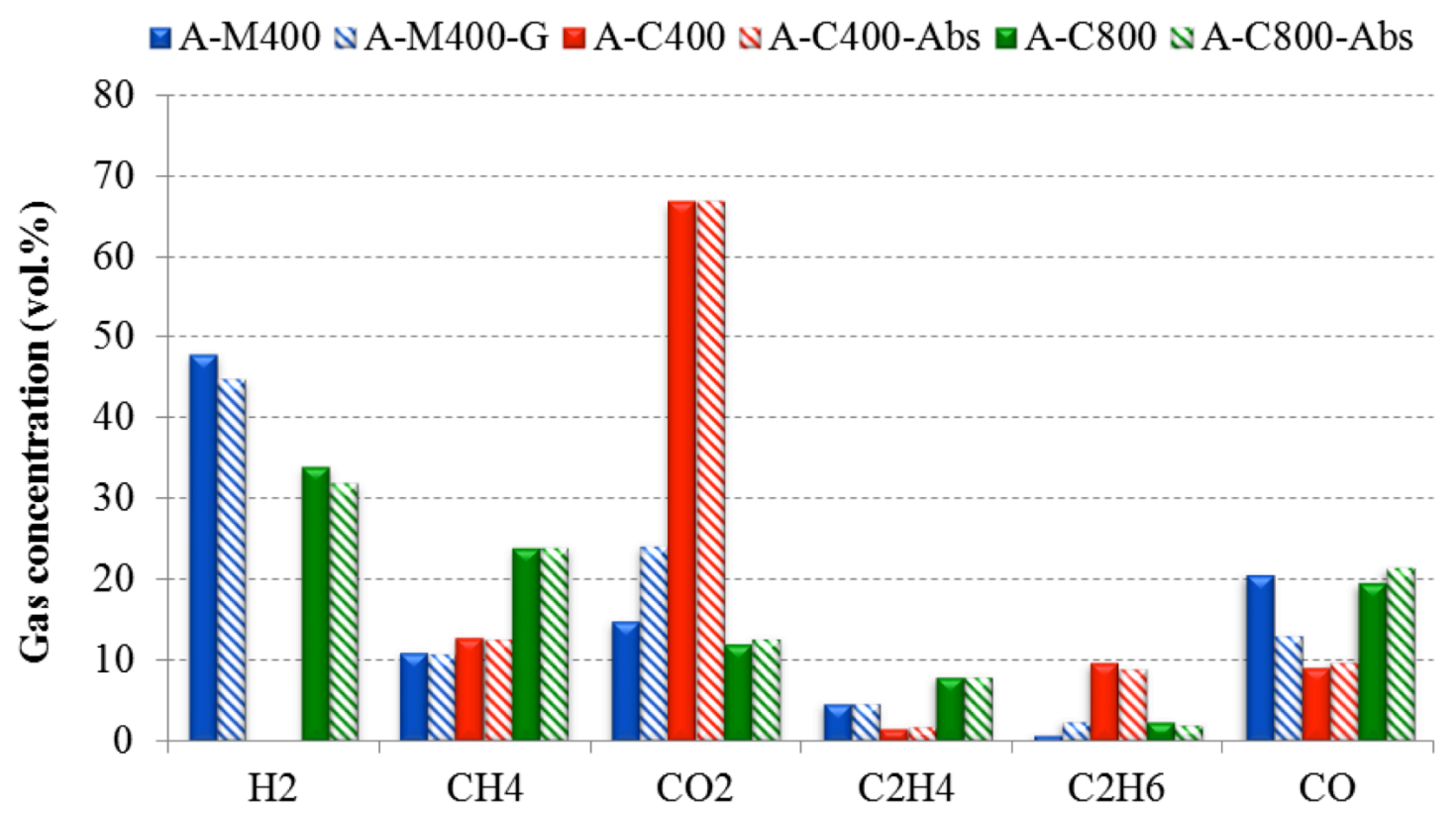

Figure 5. Gas composition (vol.\%) of the gas fraction produced in the experiments AM400, A-M400-G, A-C400, A-C400-Abs, A-C800 and A-C800-Abs.

\subsection{Heating values of the pyrolysis gases}

Higher heating values (HHV) were calculated from the mean of the individual heating values of the compounds present in the gas fraction. Figure 6 shows the energy content of the gas fraction per gram of pyrolysed material $\left(E_{g}\right)$ under conventional and microwave heating, which was calculated from HHV. This bubble graph presents a 
global view of the gas yield (expressed as wt.\%) and syngas content (expressed as vol.\%). The size of the bubble represents $\mathrm{E}_{\mathrm{g}}$. It is evident from the diagram that microwave heating provides a gas with a higher $\mathrm{E}_{\mathrm{g}}$ than in conventional heating, as in the case of the gas yield and syngas production.

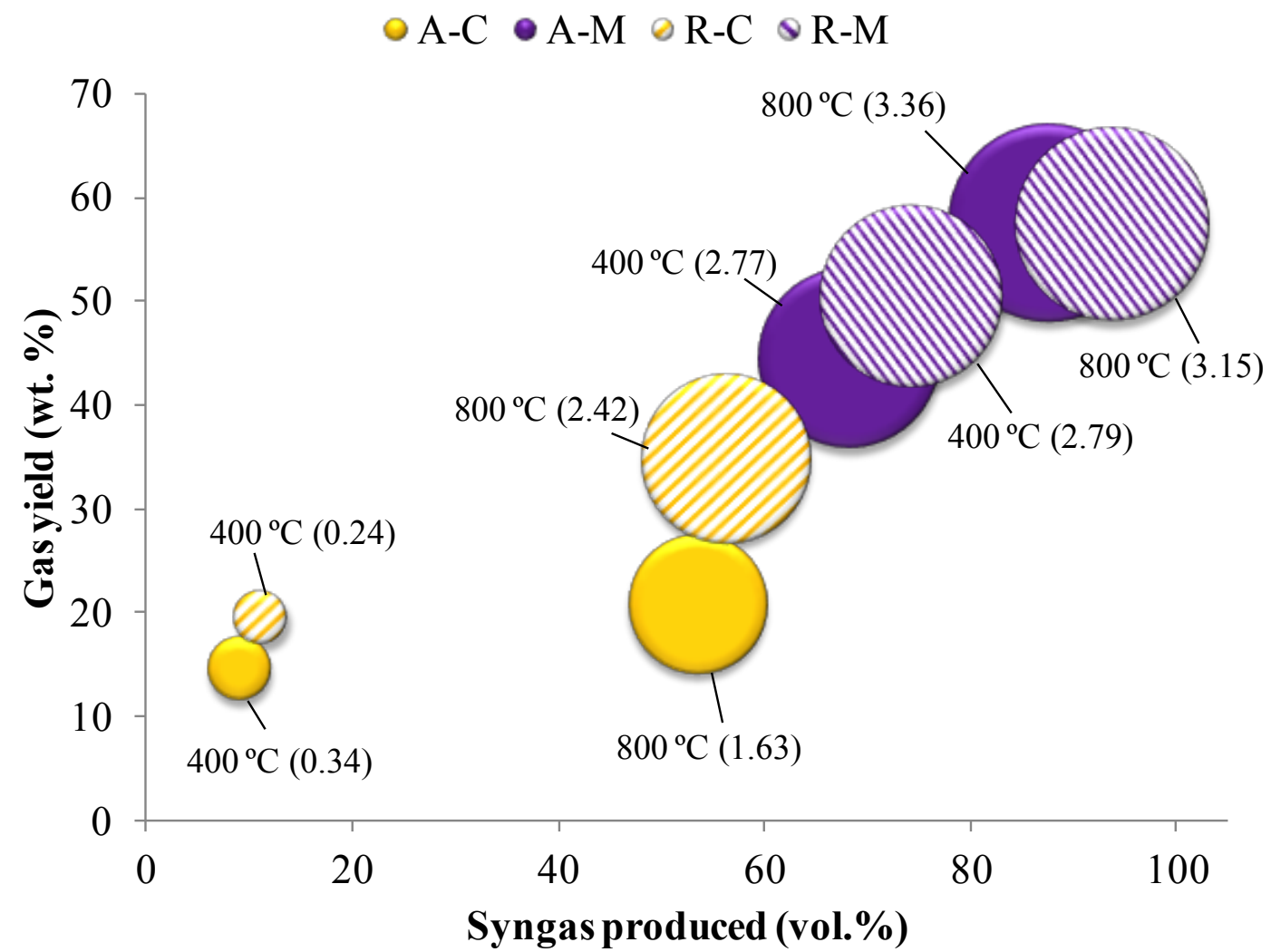

Figure 6. Comparative diagram between the gas yield (wt.\%) and syngas production (vol.\%) during the pyrolysis of the microalga and its residue by CP and MIP. The size of the bubble represents the $\mathrm{E}_{\mathrm{g}}$ values $\left(\mathrm{Wh} \mathrm{g}^{-1}\right.$ ), which are shown between parentheses, after the pyrolysis temperature.

The optimal conditions appear when the highest values for gas yield and syngas content are reached. These values were obtained in experiments A-M800 (57.5 wt.\% of gas yield and 87.7 vol.\% of syngas) and R-M800 (57.2 wt.\% of gas yield and 93.8.vol \% of syngas), which gave $\mathrm{E}_{\mathrm{g}}$ values of 3.36 and $3.15 \mathrm{Wh} \mathrm{g}^{-1}$, respectively. 
The effect of pyrolysis temperature on $\mathrm{E}_{\mathrm{g}}$ is considerable. If the pyrolysis temperature rises, the $\mathrm{E}_{\mathrm{g}}$ increases, especially in $\mathrm{CP}$. If we compare both materials when pyrolysed by means of conventional heating, in $\mathrm{A}$ the $\mathrm{E}_{\mathrm{g}}$ is almost five times higher with a rise in the pyrolysis temperature from 400 to $800{ }^{\circ} \mathrm{C}$, whereas in $\mathrm{R}$, this difference is ten times higher. However, these differences are made to appear almost insignificant when compared to the values reached by microwave heating.

The $\mathrm{E}_{\mathrm{g}}$ values obtained are rather low compared to those of other fossil fuels, such as natural gas (15.6 $\mathrm{Wh} \mathrm{g}^{-1}$ gas). However, attention needs to be paid to the units in which $E_{\mathrm{g}}$ is expressed. The results in this paper have been normalized per gram of raw material instead of per gram of gas produced. In the case just metioned, the best $\mathrm{E}_{\mathrm{g}}$ would be 5.8 $\mathrm{Wh} \mathrm{g}^{-1}$ gas. Similar $\mathrm{E}_{\mathrm{g}}$ values have been obtained with other biomass materials (Raveendran and Ganesh, 1996). Moreover, the $\mathrm{E}_{\mathrm{g}}$ values of this study are comparable to those achieved with synthetic coal gas or blast furnace gas (Perry and Green, 1997). Nevertheless, it is important to note that the goal of the pyrolysis processes performed herein is to maximise the syngas production, which do not have particularly high energy content, but can be used for many other applications different from its use as direct fuel. These include hydrogen and methanol production, Fischer-Tropsch and synthesis of biopolymers via bacterial fermentation of syngas, among others (Bridgwater, 2012; http://www.synpol.org/). 


\section{Conclusions}

This study has demonstrated the great potential of microalgae and their extraction residue for use as hydrogen and syngas source via microwave induced pyrolysis. The MIP of the residue at $800{ }^{\circ} \mathrm{C}$ was found to be optimal for attaining a maximum syngas concentration (93.8 vol.\%), whereas the MIP of microalga at $400{ }^{\circ} \mathrm{C}$ produced the gas fraction with the highest $\mathrm{H}_{2} / \mathrm{CO}$ ratio (2.3). The drastic differences in fraction yields and product distribution between CP and MIP in this work provide convincing evidence of the superiority of MIP for syngas and $\mathrm{H}_{2}$ production, even at low temperatures.

\section{Acknowledgements}

Financial support from the CDTI and EXELERIA (Project CENIT-VIDA), MEC Spain INNPACTO (Project CMICROWAVES IPT-2011-0739-920000) and from the European Union Seventh Framework Programme (FP7/2007-2013) under agreement $n^{\circ}$ 311815 is acknowledged. JMB also acknowledges the support received from the CSIC JAE Program.

\section{References}

1. Brennan, L., Owende, P., 2010. Biofuels from microalgae-A review of technologies for production, processing, and extractions of biofuels and coproducts. Renew. Sustain. Energy Rev. 14, 557-577.

2. Bridgwater, A.V., 2012. Review of fast pyrolysis of biomass and product upgrading. Biomass Bioenergy 38, 68-94.

3. Campanella, A., Muncrief, R., Harold, M.P., Griffith, D.C., Whitton, N.M., Weber, R.S., 2012. Thermolysis of microalgae and duckweed in a CO 2- 
swept fixed-bed reactor: Bio-oil yield and compositional effects.

Bioresource Technology 109, 154-162.

4. Campbell, P.K., Beer, T., Batten, D., 2011. Life cycle assessment of biodiesel production from microalgae in ponds. Bioresour. Technol. 102, 50-56.

5. Carriquiry, M.A., Du, X., Timilsina, G.R., 2011. Second generation biofuels: Economics and policies. Energy Policy 39, 4222-4234.

6. Chisti, Y., 2007. Biodiesel from microalgae. Biotechnol. Adv. 25, 294-306.

7. Delrue, F., Setier, P.A., Sahut, C., Cournac, L., Roubaud, A., Peltier, G., Froment, A.K., 2012. An economic, sustainability, and energetic model of biodiesel production from microalgae. Bioresour. Technol. 111, 191-200.

8. Domínguez, A., Menéndez, J.A., Fernández, Y., Pis, J.J., Nabais, J.M.V., Carrott, P.J.M., Carrott, M.M.L.R., 2007. Conventional and microwave induced pyrolysis of coffee hulls for the production of a hydrogen rich fuel gas. J. Anal. Appl. Pyrolysis 79, 128-135.

9. Domínguez, A., Menéndez, J.A., Inguanzo, M., Pis, J.J., 2005. Investigations into the characteristics of oils produced from microwave pyrolysis of sewage sludge. Fuel Process. Technol. 86, 1007-1020.

10. Domínguez, A., Menéndez, J.A., Inguanzo, M., Pís, J.J., 2006. Production of bio-fuels by high temperature pyrolysis of sewage sludge using conventional and microwave heating. Bioresour. Technol. 97, 1185-1193.

11. Du, Z., Li, Y., Wang, X., Wan, Y., Chen, Q., Wang, C., Lin, X., Liu, Y., Chen, P., Ruan, R., 2011. Microwave-assisted pyrolysis of microalgae for biofuel production. Bioresour. Technol. 102, 4890-4896.

12. Encinar, J.M., Beltrán, F.J., Bernalte, A., Ramiro, A., González, J.F., 1996. Pyrolysis of two agricultural residues: Olive and grape bagasse. Influence of particle size and temperature. Biomass Bioenergy 11, 397-409.

13. Fernández, Y., Arenillas, A., Bermúdez, J.M., Menéndez, J.A., 2010. Comparative study of conventional and microwave-assisted pyrolysis, steam and dry reforming of glycerol for syngas production, using a carbonaceous catalyst. J. Anal. Appl. Pyrolysis 88, 155-159.

14. Fernández, Y., Arenillas, A., Díez, M.A., Pis, J.J., Menéndez, J.A., 2009. Pyrolysis of glycerol over activated carbons for syngas production. J. Anal. Appl. Pyrolysis 84, 145-150.

15. Ferrel, J., Sarisky-Reed, V., 2010. National Algal Biofuels Technology Roadmap. U.S. Department of Energy.

16. Grierson, S., Strezov, V., Shah, P., 2011. Properties of oil and char derived from slow pyrolysis of Tetraselmis chui. Bioresour. Technol. 102, 82328240.

17. Harun, R., Davidson, M., Doyle, M., Gopiraj, R., Danquah, M., Forde, G., 2011. Technoeconomic analysis of an integrated microalgae photobioreactor, biodiesel and biogas production facility. Biomass Bioenergy 35, 741-747.

18. http://www.synpol.org/, SYNPOL project: Biopolymers from Syngas Fermentation.

19. Hu, Z., Ma, X., Chen, C., 2012. A study on experimental characteristic of microwave-assisted pyrolysis of microalgae. Bioresour. Technol. 107, 487493. 
20. Lardon, L., Hélias, A., Sialve, B., Steyer, J.P., Bernard, O., 2009. Life-cycle assessment of biodiesel production from microalgae. Environ. Sci. Technol. $43,6475-6481$.

21. Luque, R., Menéndez, J.A., Arenillas, A., Cot, J., 2012. Microwave-assisted pyrolysis of biomass feedstocks: The way forward? Energy Environ. Sci. 5, 5481-5488.

22. Menéndez, J.A., Juárez-Pérez, E.J., Ruisánchez, E., Bermúdez, J.M., Arenillas, A., 2011. Ball lightning plasma and plasma arc formation during the microwave heating of carbons. Carbon 49, 346-349.

23. Menéndez, J.A., Menéndez, E.M., García, A., Parra, J.B., Pis, J.J., 1999. Thermal treatment of active carbons: A comparison between microwave and electrical heating. J. Microw. Power Electromagn. Energy 34, 137-143.

24. Miao, X., Wu, Q., 2004. High yield bio-oil production from fast pyrolysis by metabolic controlling of Chlorella protothecoides. J. Biotechnol. 110, 85-93.

25. Miao, X., Wu, Q., Yang, C., 2004. Fast pyrolysis of microalgae to produce renewable fuels. J. Anal. Appl. Pyrolysis 71, 855-863.

26. Perry, R.H., Green, D.W., 1997. Perry's Chemical Engineers' Handbook, seventh ed. McGraw-Hill, New York.

27. Raveendran, K., Ganesh, A., 1996. Heating value of biomass and biomass pyrolysis products. Fuel 75, 1715-1720.

28. Sanchez-Silva, L., López-González, D., Garcia-Minguillan, A.M., Valverde, J.L., 2013. Pyrolysis, combustion and gasification characteristics of Nannochloropsis gaditana microalgae. Bioresour. Technol. 130, 321-331.

29. Tabernero, A., Martín del Valle, E.M., Galán, M.A., 2012. Evaluating the industrial potential of biodiesel from a microalgae heterotrophic culture: Scale-up and economics. Biochem. Eng. J. 63, 104-115.

30. Thangalazhy-Gopakumar, S., Adhikari, S., Chattanathan, S.A., Gupta, R.B., 2012. Catalytic pyrolysis of green algae for hydrocarbon production using $\mathrm{H}$ +ZSM-5 catalyst. Bioresour. Technol. 118, 150-157.

31. Wang, K., Brown, R.C., Homsy, S., Martinez, L., Sidhu, S.S., 2013. Fast pyrolysis of microalgae remnants in a fluidized bed reactor for bio-oil and biochar production. Bioresour. Technol. 127, 494-499.

32. Wang, X.H., Chen, H.P., Ding, X.J., Yang, H.P., Zhang, S.H., Shen, Y.Q., 2009. Properties of gas and char from microwave pyrolysis of pine sawdust. BioResources 4, 946-959.

33. Xu, L., Wim Brilman, D.W.F., Withag, J.A.M., Brem, G., Kersten, S., 2011. Assessment of a dry and a wet route for the production of biofuels from microalgae: Energy balance analysis. Bioresour. Technol. 102, 5113-5122.

34. Zanzi, R., Sjöström, K., Björnbom, E., 2002. Rapid pyrolysis of agricultural residues at high temperature. Biomass Bioenergy 23, 357-366.

35. Zhang, X., Hayward, D.O., Mingos, D.M.P., 2003. Effects of microwave dielectric heating on heterogeneous catalysis. Catal. Lett. 88, 33-38. 